\title{
Effect of P450 Oxidoreductase Polymorphisms on the Metabolic Activities of Ten Cytochrome P450s Varied by Polymorphic CYP Genotypes in Human Liver Microsomes
}

\author{
Yan Fang Na Gao Xin Tian Jun Zhou Hai-Feng Zhang Jie Gao Xiao-Pei He \\ Qiang Wen Lin-Jing Jia Han Jin Hai-Ling Qiao
}

Institute of Clinical Pharmacology, Zhengzhou University, Henan, China

\section{Key Words}

Por - Gene polymorphism - Cytochrome P450 - CYP genotypes - Human liver microsomes • Drug metabolism

\begin{abstract}
Background/ Aims: Little is known about the effect of P450 oxidoreductase (POR) gene polymorphisms on the activities of CYPs with multiple genotypes. Methods: We genotyped 102 human livers for 18 known POR single nucleotide polymorphisms (SNPs) with allelic frequencies greater than $1 \%$ as well as for 27 known SNPs in 10 CYPs. CYP enzyme activities in microsomes prepared from these livers were determined by measuring probe substrate metabolism by high performance liquid chromatograph. Results: We found that the effects of the 18 POR SNPs on 10 CYP activities were CYP genotype-dependent. The POR mutations were significantly associated with decreased overall $\mathrm{K}_{\mathrm{m}}$ for CYP2B6 and 2E1, and specific genotypes within CYP1A2, 2A6, 2B6, 2C8, 2D6 and 2E1 were identified as being affected by these POR SNPs. Notably, the effect of a specific POR mutation on the activity of a CYP genotype could not be predicted from other CYP genotypes of even the same CYP. When combining one $P O R$ SNP with other POR SNPs, a hitherto unrecognized effect of multiple-site $P O R$ gene polymorphisms (MSGP) on CYP activity was uncovered, which was not necessarily consistent with the effect of either single POR SNP. Conclusions: The effects of POR SNPs on CYP activities were not only CYP-dependent, but more importantly, CYP genotype-dependent. Moreover, the effect of a POR SNP alone and in combination with other POR SNPs (MSGP) was not always consistent, nor predictable. Understanding the impact of $P O R$ gene polymorphisms on drug metabolism necessitates knowing the complete SNP complement of POR and the genotype of the relevant CYPS.




\section{Cellular Physiology Cell Physiol Biochem 2018;47:1604-1616 \begin{tabular}{l|l} 
and Biochemistry Published online: June 27, 2018 & $\begin{array}{l}\text { C) } 2018 \text { The Author(s). Published by S. Karger AG, Basel } \\
\text { www.karger.com/cpb }\end{array}$
\end{tabular}}

Fang et al.: POR Polymorphism Affect Polymorphic Cyps

\section{Introduction}

P450 oxidoreductase (POR) is located on the smooth endoplasmic reticulum where it donates electrons to several oxygenase enzymes, including cytochrome P450 (CYP) [1]. CYPs, especially those in families 1-3 account for the oxidation of approximately $70-80 \%$ of the clinically used drugs [2]. As the principal electron donor to the CYPs, POR is essential for CYP activity [3].

The human $P O R$ gene is highly polymorphic, with 48 alleles identified on the $P O R$ allele nomenclature web page (http://www.cypalleles.ki.se/por.htm), and 140 POR single nucleotide polymorphism (SNPs) were detected among 842 individuals from four ethnicities [4]. The majority of early studies on POR mutations were derived from on patients with P450 oxidoreductase deficiency in association with disordered steroidogenesis $[5,6]$. Only recently have $P O R$ polymorphisms been studied in healthy humans. Two studies [7, 8] carried out with heterologously expressed proteins revealed that $P O R A 503 \mathrm{~V}$ impaired CYP2D6 activity by $40-50 \%$ and CYP3A4 activity by $61-77 \%$. In contrast, two further studies $[9,10]$ conducted in vivo reported significantly higher CYP3A activity in association with the POR A503V mutation. However, these studies just focused on POR A503V mutation, and the reconstituted system used may not accurately model some aspects of enzyme function in a whole cell, making extrapolation to an in vivo situation difficult. Moreover, they determined CYP activity based on a single substrate concentration and could not generate complete kinetic parameters $\left(\mathrm{K}_{\mathrm{m}}, \mathrm{V}_{\text {max }}\right.$ and $\left.\mathrm{CL}_{\text {int }}\right)$.

It is well known that some human drug metabolizing CYPs are highly polymorphic. Our previous studies [11-14] performed with microsomes from 105 normal and 102 hepatocellular carcinoma liver tissue samples revealed substantial inter-individual variations in CYP content [15] and activity, also in predicted in vivo hepatic clearance. In addition, our earlier studies have confirmed the significant associations between POR content and the activities of four CYPs (CYP2B6, 2C8, 2C19, and 2E1) [16], and between cytochrome b5 content and activity of CYP1A2, 2B6 and 2E1 [17]. However, other factors that may underly the large inter-individual variation remain unknown. Several previous in vitro and in vivo studies have revealed that the effect of POR gene polymorphisms differed, depending on the specific POR mutation, the CYP isoform, and the substrate used to assay activity $[9,18,19]$. Most of these reports $[18,20]$ were concerned with the effect on the overall activity of CYP and did not examine the effects on different $C Y P$ genotypes. Only one study [10] has characterized the impact of a single common POR SNP, A503V, on the activity of the $C Y P 3 A 5^{*} 1{ }^{*} 1$ and $C Y P 3 A 5^{*} 3 /{ }^{*} 3$ genotypes in vivo. Two studies in reconstituted systems revealed different effects on CYP2C8 variants [21] and CYP2C9 variants [22]; however, these studies were performed with a very limited number of $P O R$ mutations and CYP isoforms. Human liver microsomes (HLMs) provide a valuable means to test the effect of POR polymorphisms on CYP activity because they contain the enzymes in their native environment.Unfortunately, no studies on the activities of different CYP genotypes have been conducted with HLMs. Whether POR polymorphisms result in substantially different activities with the specific polymorphic genotypes of each CYP remains to be determined.

The presence of multiple mutations in the POR gene lead us to hypothesize that these POR mutations might exert synergistic or compensating effects on CYP activity. Moreover, no studies on the effect of compounded mutations in POR have been conducted.

To this end, we performed a comprehensive study on the effect of POR gene polymorphisms on 10 CYP isoforms. Eighteen POR SNPs and the activities of 10 CYP isoforms determined by metabolism of appropriate probe drugs were carried out with HLMs from 102 subjects. In addition, the effects of multiple POR SNPs in combination (multiple site gene polymorphisms, MSGP) on the activities of the various CYP genotypes were determined. 


\section{Cellular Physiology Cell Physiol Biochem 2018;47:1604-1616

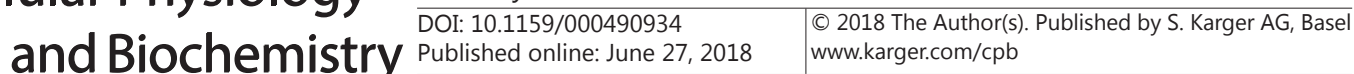

Fang et al.: POR Polymorphism Affect Polymorphic Cyps

\section{Materials and Methods}

\section{Human liver microsomes}

Human liver tissue samples ( $\mathrm{n}=102)$ were acquired from Chinese patients [17] undergoing hepatic surgery in the first affiliated hospital of Zhengzhou University and the People's Hospital of Henan Province (Table 1) and frozen in liquid nitrogen within 1 4 hrs after being collected. All liver samples were tested for and declared free of infectious agents, including human immunodeficiency virus (HIV), hepatitis B (HBV), and hepatitis C (HCV). Well-documented demographic information such as age, sex, body weight, smoking habits, alcohol consumption, and pre-surgical medication for was obtained for each patient.

\section{Ethical statement}

This study was carried out in accordance with approved guidelines of the ethics committees of Zhengzhou University with written informed consent from all subjects. All subjects gave written informed consent in accordance with the Declaration of Helsinki. The protocol was approved by Ethics Committee of the Zhengzhou University (Zhengzhou, China).

\section{Preparation of human liver microsomes}

Human liver microsomes (HLMs) were prepared by differential centrifugation. After being thawed on ice and weighed, tissue samples were homogenized on ice in Tris- $\mathrm{HCl}(\mathrm{pH} 7.0)$ buffer containing $1.12 \% \mathrm{KCl}$ $(\mathrm{w} / \mathrm{v})$ and $1.12 \%$ EDTA $(\mathrm{v} / \mathrm{v})$. The homogenate then was subjected to centrifugation at $9,000 \mathrm{x} \mathrm{g}$ for 20 $\min$ at $4^{\circ} \mathrm{C}$. The supernatant fraction was collected and submitted for a second centrifugation at $100,000 \mathrm{x}$ $\mathrm{g}$ for $1 \mathrm{~h}$ at $4^{\circ} \mathrm{C}$. After resuspension in $0.15 \mathrm{M}$ Tris- $\mathrm{HCl}(\mathrm{pH} 7.6)$ buffer, the resulting microsomal fraction was pelleted at $100,000 \mathrm{~g}$ at $4^{\circ} \mathrm{C}$ for an additional hour. The microsomal pellet was finally suspended in $0.25 \mathrm{M}$ suspension buffer, frozen in liquid nitrogen, and stored at $-80^{\circ} \mathrm{C}$ until use. Microsomal protein concentration was measured by the Bradford method [23].

\section{Genotyping of POR and CYP isoforms}

Genomic DNA was isolated from 102 liver tissues using the Charge Switch Gdna Mini Tissue Kit from Invitrogen. Eighteen polymorphisms in the POR gene with frequencies greater than $1 \%$ in the Chinese population were genotyped. Apart from rs3823884, rs2286822, rs2302432, rs2228104, which were genotyped by PCR-sequencing, all the remaining POR SNPs were determined by the Sequenom method $[24,25]$ and a total of 27 CYP gene polymorphisms (displayed as their genomic positions) including five mutations for CYP1A2 (-3860G>A, $-3113 A>G,-163 C>A, 2159 G>A$ and $5347 T>C)$, three for $C Y P 2 A 6\left[{ }^{*} 1 B,{ }^{*} 4\right.$ and $* 9(-48 T>G)]$, two for $C Y P 2 B 6(15631 G>T$ and $18053 A>G)$, two for $C Y P 2 C 8$ [ ${ }^{*} 1 B(-271 C>A)$ and $\left.{ }^{*} 1 C(-370 T>C)\right]$, one for CYP2C9*3(42614A $>C$ ), two for CYP2C19 [*2 (19154G>A) and $\left.{ }^{*} 3(17948 G>A)\right]$, three for CYP2D6 $(100 C>T, 1661 G>C$ and $2850 C>T)$,

six for CYP2E1 $(-1293 G>C$, $-1053 C>T, \quad-352 A>G, \quad-333 T>A$, $-71 G>T$ and $7632 T>A)$, two for CYP3A4 (20070T $>C$ and 20230G $>A$ ) and one for $C Y P 3 A 5^{*} 3(6986 \mathrm{~A}>\mathrm{G})$ were detected by the Sequenom method, a two-step PCR method or a PCR-sequencing method, as described previously [12]. Genotyping errors were detected by re-genotyping with a sub-sample and reproducibility was routinely greater than $99 \%$.
Table 1. Demographic information on the human liver cohort $(n=102)$

\begin{tabular}{lccc}
\hline & Subgroup & Number & Percentage(\%) \\
\hline Gender & Males & 35 & 34.3 \\
Age & Females & 67 & 65.7 \\
& Age $\geq 20$ and $\leq 45$ years & 36 & 35.3 \\
Age $>46$ and $\leq 60$ years & 59 & 57.8 \\
Smoking & Age $\geq 61$ and $\leq 75$ years & 7 & 6.86 \\
\multirow{3}{*}{ Drinking } & Nonsmoker & 92 & 90.2 \\
& smoker & 10 & 9.80 \\
Medical diagnose & Nondrinker & 93 & 91.2 \\
& Drinker & 9 & 8.82 \\
& Cavernous hemangioma of liver & 73 & 71.6 \\
& Metastaic carcinoma & 8 & 7.84 \\
Drug exposure & Cholelithiasis & 7 & 6.86 \\
& Gallbladder cancer & 4 & 3.92 \\
& Hepatic cholangiocarcinoma & 6 & 5.88 \\
& Hepatocellular carcinoma & 4 & 3.92 \\
& For all donors, only regular drugs intake preceding liver surgery, \\
& no exposure to known CYP-inducing or -inhibiting agents.
\end{tabular}




\section{CYP Enzyme Activity Assays}

For each liver sample, the activities of ten CYPs were determined by measuring the rates of each of the following reactions by high performance liquid chromatography according to previously described procedures [12] with seven or eight substrate concentrations within the following substrate concentration ranges: 6.25-800 $\mu \mathrm{M}$ phenacetin 0 -deethylation (CYP1A2), 0.156-20 $\mu \mathrm{M}$ coumarin 7-hydroxylation (CYP2A6), 7.8-500 $\mu \mathrm{M}$ bupropion1-hydroxylation (CYP2B6), 2.5-80 $\mu \mathrm{M}$ paclitaxel 6-hydroxylation (CYP2C8), 31.25-2000 $\mu \mathrm{M}$ tolbutamide 4-hydroxylation (CYP2C9), 3.9-500 $\mu \mathrm{M}$ omeprazole 4-hydroxylation (CYP2C19), 0.625-960 $\mu \mathrm{M}$ dextromethorphan O-demethylation (CYP2D6),7.8-1000 $\mu \mathrm{M}$ chlorzoxazone 6-hydroxylation (CYP2E1), and 3.9-200 $\mu \mathrm{M}$ midazolam 1'-hydroxylation (CYP3A4/5). Incubation conditions for each substrate were optimized in preliminary experiments to determine linearity with respect to incubation time, substrate concentration and protein concentration. Incubation mixtures contained HLMs (0.3mg protein $/ \mathrm{ml}$ for CYP1A2, 2A6, and 2E1; $0.2 \mathrm{mg}$ protein $/ \mathrm{ml}$ for CYP2D6 and 3A4/5; 0.5mg protein/ml for CYP2B6, 2C8, 2C9 and 2C19), $100 \mathrm{mM}$ phosphate buffer ( $\mathrm{pH} 7.4$ ), and 1mM NADPH. Optimal incubation times were as follows: $30 \mathrm{~min}$ for CYP1A2, 2A6, 2E1; $60 \mathrm{~min}$ for CYP2B6, 2C9; $90 \mathrm{~min}$ for CYP2C19; $120 \mathrm{~min}$ for CYP2C8; 20 min for CYP2D6 and 5 min for CYP3A4/5. All the incubations were linear within incubation time. Metabolites were determined by HPLC-UV or HPLC-FLD. All experiments included two replicates. The $\mathrm{K}_{\mathrm{m}}$ and $\mathrm{V}_{\max }$ of each microsomal CYP was determined by nonlinear regression analysis using GraphPad Prism 5 and the $\mathrm{CL}_{\text {int }}$ was calculated from the ratio of $\mathrm{V}_{\max }$ to $\mathrm{K}_{\mathrm{m}}$.

\section{Statistical Analysis}

The $\chi^{2}$ test for goodness-of-fit was used to check whether the distribution of genotypes in HLMs deviated from the Hardy-Weinberg equilibrium. The initial rate of metabolite formation for each CYP Michaelis constant $\left(\mathrm{K}_{\mathrm{m}}\right)$ and maximum velocity $\left(\mathrm{V}_{\max }\right)$ values were determined by nonlinear regression analysis using GraphPad Prism5. Intrinsic clearance $\left(\mathrm{CL}_{\text {int }}\right)$ was calculated from the ratio of $\mathrm{V}_{\max }$ to $\mathrm{K}_{\mathrm{m}}$. The Shapiro-Wilk test of normality was used to check the distribution shape of $\mathrm{CL}_{\text {int }}, \mathrm{K}_{\mathrm{m}}$ and $\mathrm{V}_{\max }$ for each individual CYP enzyme. Mean-rank' post hoc multiple comparisons were carried out with the Kruskal-Wallis $H$ test using SPSS statistics 21 software. An adjusted $P$ value $<0.05$ was considered statistically significant (two-tailed).

\section{Results}

\section{POR Gene Polymorphisms}

Frequency of POR SNPs. A total of 18 POR SNPs were genotyped in 102 HLMs with allelic frequencies ranging from $0.98 \%$ to $88.3 \%$ (Table 2). There were 13 SNPs with allele frequencies greater than 10\%. All POR SNPs were in Hardy-Weinberg equilibrium $(P>0.05)$. For rs3815455, rs41301394 and rs1057868, the genotype could be determined in 98, 96 and 100 of the samples, respectively; 83 of these samples yielded a genotype for all three SNPs. Genotypes for rs4732515, rs4732516 and rs2302431 could be determined in 99, 96 and 98 samples, respectively, and all three genotypes could be determined in 80 samples. For rs2302432 and rs2228104, 99 and101 samples could be genotyped, respectively, and both SNP genotypes could be determined in 99 samples. All the remaining polymorphisms were found in all 102 samples.

Linkage Disequilibrium Analysis. Linkage disequilibrium (LD) analysis was performed by the $r^{2}$ and $\left|D^{\prime}\right|$ statistics. For $r^{2}$ values, perfect linkage $\left(r^{2}=1\right)$ was detected between rs10239977 and rs1057870, among rs3815455, rs41301394 and rs1057868, and among rs4732515, rs4732516 and rs2302431 (Fig.1). Relatively strong linkage $\left(r^{2} \geq 0.95\right)$ was observed between rs2302432 and rs2228104, with the two variants differing in just one sample.

Effect of POR single nucleotide polymorphisms (SNPs)

Effect on CYP overall Activity. When assessing the effect of POR SNPs on CYP activities, we ruled out SNPs rs17148944, rs41301427, rs10239977, rs1057870 for their low allele frequencies and took rs1057868 and rs4732515 to represent rs3815455-rs41301394- 
Fang et al.: POR Polymorphism Affect Polymorphic Cyps

Table 2. Gene polymorphisms of POR in human liver microsomes. Genomic positions, coding position, amino acid change, location and allele were compiled from studies Hart et al., 2008; Huang et al., 2008; Gomes et al., 2009, Tomková et al., 2012 and Sim et al., 2009. =: Silent mutation; 5'-UTR, 5'-untranslated region. ",\#, $\mathbf{\Delta r e -}$ fer to perfect linkage ( $\left.r^{2}=1\right)$ observed between rs 10239977 and rs1057870, among rs 3815455 , rs41301394 and rs1057868, among rs4732515, rs4732516 and rs2302431. •refer to strong linkage $\left(\mathrm{r}^{2} \geq 0.95\right)$ observed between rs2302432 and rs2228104, with the two variants differing in just one sample. For rs3815455, rs41301394 and rs1057868, the genotype could be determined in 98,96 and 100 of the samples, respectively; 83 of these samples yielded a genotype for all three SNPs. For rs4732515, rs4732516 and rs2302431, genotypes could be determined in 98, 96 and 100 of the samples, respectively; and all three genotypes could be determined in 80 samples. For rs2302432 and rs2228104, 99 and101 samples could be genotyped, respectively, and both SNP genotypes could be determined 99 samples. For the rest polymorphisms, all the 102 samples could be detected. To support readability of the following analysis, POR SNP1, SNP2, SNP3, SNP4, SNP5, SNP6, SNP7, SNP8, SNP9 were used to represent rs3823884, rs1135612, rs10954732, rs4732515, rs2286822, rs2286823, rs2302432, rs1057868, rs2302433, respectively, for the latter analysis

\begin{tabular}{|c|c|c|c|c|c|c|c|c|c|}
\hline $\begin{array}{l}\text { (rs number/ } \\
\text { SNP ID) }\end{array}$ & Allele & Location & $\begin{array}{l}\text { Genomic } \\
\text { position }\end{array}$ & $\begin{array}{c}\text { Coding } \\
\text { position }\end{array}$ & $\begin{array}{l}\text { Amino acid } \\
\text { change }\end{array}$ & \multicolumn{3}{|c|}{$\begin{array}{c}\text { Genotype Frequency } \\
\text { Genotype n Frequency(\%) }\end{array}$} & Variant allele Frequency $(\%)$ \\
\hline rs3823884 & & 5'-UTR & $5036 \mathrm{~A}>\mathrm{C}$ & $-47 A>C$ & & AA & 54 & 52.9 & 27.0 \\
\hline \multirow{2}{*}{ (SNP1) } & & & & & & $\mathrm{AC}$ & 41 & 40.2 & \\
\hline & & & & & & CC & 7 & 6.9 & \\
\hline \multirow[t]{3}{*}{ rs17148944 } & & Intron 2 & $62448 \mathrm{G}>\mathrm{A}$ & $237+88 \mathrm{G}>\mathrm{A}$ & & GG & 100 & 98.0 & 0.98 \\
\hline & & & & & & GA & 2 & 2.0 & \\
\hline & & & & & & AA & 0 & 0 & \\
\hline \multirow[t]{3}{*}{ rs10239977 } & & Intron 3 & $69567 \mathrm{C}>\mathrm{T}$ & $366+89 \mathrm{C}>\mathrm{T}$ & & CC & 93 & 91.2 & $4.4^{*}$ \\
\hline & & & & & & CT & 9 & 8.8 & \\
\hline & & & & & & TT & 0 & 0 & \\
\hline \multirow{3}{*}{$\begin{array}{l}\text { rs1135612 } \\
\text { (SNP2) }\end{array}$} & & Exon 4 & $70258 \mathrm{~A}>\mathrm{G}$ & $387 \mathrm{~A}>\mathrm{G}$ & Pro129= & $\mathrm{AA}$ & 28 & 27.4 & 47.1 \\
\hline & & & & & & $\mathrm{AG}$ & 52 & 51.0 & \\
\hline & & & & & & GG & 22 & 21.6 & \\
\hline rs10954732 & & Intron 6 & $71730 \mathrm{G}>\mathrm{A}$ & $931+225 \mathrm{G}>A$ & & GG & 23 & 22.5 & 49.0 \\
\hline \multirow[t]{2}{*}{ (SNP3) } & & & & & & GA & 58 & 56.9 & \\
\hline & & & & & & AA & 21 & 20.6 & \\
\hline \multirow[t]{3}{*}{ rs3815455 } & & Intron 7 & $72337 \mathrm{C}>\mathrm{T}$ & $830+116 C>T$ & & $\mathrm{CC}$ & 36 & 43.4 & $33.7 \#$ \\
\hline & & & & & & СT & 38 & 45.8 & \\
\hline & & & & & & TT & 9 & 10.8 & \\
\hline \multirow[t]{3}{*}{ rs41301394 } & & Intron 7 & $73384 \mathrm{C}>\mathrm{T}$ & $831-35 \mathrm{C}>\mathrm{T}$ & & $\mathrm{CC}$ & 36 & 43.4 & $33.7 \#$ \\
\hline & & & & & & СT & 38 & 45.8 & \\
\hline & & & & & & TT & 9 & 10.8 & \\
\hline rs4732515 & & Intron 9 & $74610 \mathrm{~T}>\mathrm{C}$ & $1067-66 \mathrm{~T}>\mathrm{C}$ & & TT & 0 & 0 & $87.5^{\wedge}$ \\
\hline \multirow[t]{2}{*}{ (SNP4) } & & & & & & TC & 20 & 25 & \\
\hline & & & & & & CC & 60 & 75 & \\
\hline \multirow[t]{3}{*}{ rs4732516 } & & Intron 9 & $74663 \mathrm{C}>\mathrm{G}$ & $1067-13 \mathrm{C}>\mathrm{G}$ & & $\mathrm{CC}$ & 0 & 0 & $87.5^{\mathbf{A}}$ \\
\hline & & & & & & CG & 20 & 25 & \\
\hline & & & & & & GG & 60 & 75 & \\
\hline rs2286822 & & Intron 10 & $74869 \mathrm{C}>\mathrm{T}$ & $1248+12 C>T$ & & CC & 25 & 25 & 52.0 \\
\hline \multirow[t]{2}{*}{ (SNP5) } & & & & & & CT & 46 & 46 & \\
\hline & & & & & & TT & 29 & 29 & \\
\hline rs2286823 & & Intron 10 & $74877 \mathrm{G}>\mathrm{A}$ & $1248+20 G$ & & GG & 23 & 22.5 & 51.5 \\
\hline \multirow[t]{2}{*}{ (SNP6) } & & & & & & GA & 53 & 52.0 & \\
\hline & & & & & & AA & 26 & 25.5 & \\
\hline \multirow[t]{3}{*}{ rs41301427 } & & Intron 11 & $75138 \mathrm{G}>\mathrm{A}$ & $1398+32 \mathrm{G}>\mathrm{A}$ & & GG & 99 & 97.1 & 1.47 \\
\hline & & & & & & $\mathrm{GA}$ & 3 & 2.9 & \\
\hline & & & & & & AA & 0 & 0 & \\
\hline \multirow[t]{3}{*}{ rs2302431 } & & Intron 11 & $75444 \mathrm{~T}>\mathrm{C}$ & $1399-34 \mathrm{~T}>\mathrm{C}$ & & TT & 0 & 0 & $87.5^{\boldsymbol{\Lambda}}$ \\
\hline & & & & & & $\mathrm{TC}$ & 20 & 25 & \\
\hline & & & & & & $\mathrm{CC}$ & 60 & 75 & \\
\hline rs2302432 & & Intron 11 & $75445 \mathrm{G}>\mathrm{T}$ & $1399-34 \mathrm{~T}>\mathrm{C}$ & & GG & 0 & 0 & $88.3^{\bullet}$ \\
\hline \multirow[t]{2}{*}{ (SNP7) } & & & & & & GT & 23 & 23.2 & \\
\hline & & & & & & TT & 76 & 76.8 & \\
\hline \multirow[t]{3}{*}{ rs2228104 } & & Exon 12 & $75534 \mathrm{~T}>\mathrm{C}$ & $1455 \mathrm{~T}>\mathrm{C}$ & Ala485= & TT & 0 & 0 & $87.9^{\circ}$ \\
\hline & & & & & & TC & 24 & 24.2 & \\
\hline & & & & & & CC & 75 & 75.8 & \\
\hline rs1057868 & POR*28 & Exon 12 & $75587 \mathrm{C}>\mathrm{T}$ & $1508 \mathrm{C}>\mathrm{T}$ & Ala503Val & CC & 36 & 43.4 & $33.7 \#$ \\
\hline \multirow[t]{2}{*}{ (SNP8) } & & & & & & CT & 38 & 45.8 & \\
\hline & & & & & & TT & 9 & 10.8 & \\
\hline rs2302433 & & Intron 12 & $75781 \mathrm{C}>\mathrm{T}$ & $1669+33 \mathrm{C}>\mathrm{T}$ & & CC & 90 & 88.2 & 6.37 \\
\hline (SNP9) & & & & & & CT & 11 & 10.8 & \\
\hline & & & & & & TT & 1 & 1.0 & \\
\hline rs1057870 & & Exon 13 & $75868 \mathrm{G}>\mathrm{A}$ & $1716 \mathrm{G}>\mathrm{A}$ & Ser572= & GG & 93 & 91.2 & $4.4^{*}$ \\
\hline & & & & & & $\mathrm{GA}$ & 9 & 8.8 & \\
\hline & & & & & & AA & 0 & 0 & \\
\hline
\end{tabular}


rs1057868 and rs4732515-rs4732516-rs2302431, respectively, given their perfect linkages. We also let rs2302432 represent rs2302432-rs2228104 due to their relatively strong linkage noted above. To support readability of the following analysis, we use $P O R$ SNP1, SNP2, SNP3, SNP4, SNP5, SNP6, SNP7, SNP8, SNP9 (Fig. 1) to represent rs3823884, rs1135612, rs10954732, rs4732515, rs2286822, rs2286823, rs2302432, rs1057868, and rs2302433, respectively. We only report results with a significance level of $P<0.05$.

None of the tested $P O R$ SNPs showed a significant impact on overall activities of CYP1A2, 2A6, 2C8, 2C9, 2C19, 2D6 and 3A4/5. Conversely, CYP2B6 and 2E1 were significantly influenced by some POR SNPs (Table 3). SNP2 and SNP8 were associated with significantly decreased substrate $\mathrm{K}_{\mathrm{m}}$ for CYP2E1 and CYP2B6, respectively. $\mathrm{K}_{\mathrm{m}}$ for CYP2E1 decreased to $82 \%$ in the POR SNP2 GG group compared with SNP2 wild type. As for CYP2B6, when compared with POR SNP8 CT, $\mathrm{K}_{\mathrm{m}}$ decreased to $66 \%$ in TT group.

Effect on the Activity of Polymorphic CYPS. The effect of POR SNPs on CYP enzyme activities varied with POR SNP and CYP genotype. SNP7 showed a significant impact on the activities of the highest number of CYPs. Significantly altered activities of CYPs, including CYP1A2, 2B6 and 2D6 were associated with POR SNP7. SNP2, SNP3 and SNP8 showed a significant impact on the activities of 2 CYPs. SNP2 showed significant impact on activities of CYP2D6 and 2E1. SNP3 revealed a significant impact on activities of CYP2A6 and 2E1. Moreover, activities of CYPs including CYP2A6 and 2C8 were significantly affected by SNP8. SNP1, SNP4, SNP5 and SNP9 only elicited a significant effect on one CYP (Table 4). For the 10 polymorphic $C Y P$ isoforms, only the genotypes for which the $\mathrm{K}_{\mathrm{m}}, \mathrm{V}_{\max }$ and/or $\mathrm{CL}_{\mathrm{int}}$ was significantly affected by the POR SNPs are shown.

SNP1 was significantly associated with dramatically decreased enzyme activities for samples genotyped as CYP1A2-3860GA, as evidenced by the $\mathrm{CL}_{\text {int }}$ for CYP1A2 -3860GA genotype in the SNP1 AC group decreasing by 53\% when compared with the AA group.

SNP2 was associated with a significantly increased $\mathrm{K}_{\mathrm{m}}$ for CYP2D6 1661GG and decreased $\mathrm{K}_{\mathrm{m}}$ for CYP2E1 -333TA. The $\mathrm{K}_{\mathrm{m}}^{\mathrm{m}}$ of the CYP2D6 $1661 G G$ genotype increased to $228 \%$ in SNP2 GG group as compared with AA group. Moreover, SNP2 was also associated with decreased $\mathrm{K}_{\mathrm{m}}$ by $44 \%$ for CYP2E1-333TA in SNP2 GG when compared with AA group $(\mathrm{P}=0.009)$.

SNP3 was significantly associated with profoundly

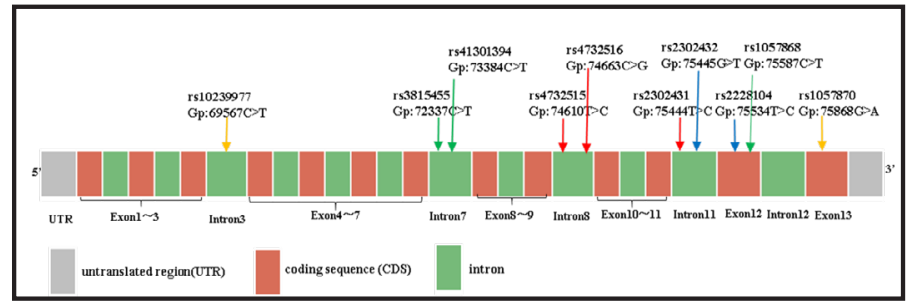

Fig. 1. Linkage disequilibrium of SNPs in POR gene. Gp, Genomic position. Arrow in red, green and yellow refer to perfect linkage $\left(r^{2}=1\right)$ observed among rs4732515, rs4732516 and rs2302431, among rs3815455, rs41301394 and rs1057868, between rs10239977 and rs1057870. Blue arrow refer to strong linkage $\left(r^{2} \geq 0.95\right)$ observed between rs2302432 and rs2228104, with the two variants differing in just one sample.

Table 3. Effect of POR SNPs on overall $\mathrm{K}_{\mathrm{m}}, \mathrm{V}_{\max }$, and $\mathrm{CL}_{\text {int }}$ of 10 CYPs. For all CYPs, only CYP of which the overall $\mathrm{K}_{\mathrm{m}}, \mathrm{V}_{\text {max }}$ and/or $\mathrm{CL}_{\text {int }}$ are/is significantly affected by POR SNPs are shown. SNP, Single Nucleotide Polymorphism; $\mathrm{K}_{\mathrm{m}}$ values are in $\mu \mathrm{M} ; \mathrm{V}_{\max }$ values are in $\mathrm{pmol} \cdot \mathrm{min}^{-1} \cdot \mathrm{mg}^{-1}$ protein; $\mathrm{CL}_{\text {int }}$ values are in $\mu \mathrm{l} \cdot \mathrm{min}^{-1} \cdot \mathrm{mg}^{-1}$ protein. SNP2, rs1135612; SNP8, rs1057868; ${ }^{\mathrm{P}} \mathrm{P}=0.022$ vs SNP2 AA ; ${ }^{\mathrm{b}} \mathrm{P}=0.018$ vs SNP8 CT. All the P value are the adjusted one after correction

\begin{tabular}{|c|c|c|c|c|c|c|}
\hline POR SNP & CYP & POR genotype & $\mathrm{n}$ & $\mathrm{Km}(\mu \mathrm{M})$ & $\begin{array}{c}\text { Vmax }(\mathrm{pmol} \cdot \mathrm{min}-1 \cdot \\
\text { mg-1 protein) }\end{array}$ & $\begin{array}{c}\text { CLint }(\mu \mathrm{l} \cdot \min -1 \cdot \\
\text { mg-1 protein })\end{array}$ \\
\hline SNP2 & CYP2E1 & AA & 28 & $60(42 \sim 177)$ & 485(297 1844) & $9.1(1.9 \sim 39.0)$ \\
\hline \multirow[t]{2}{*}{$(A>G)$} & & $\mathrm{AG}$ & 52 & $53(29 \sim 96)$ & $544(163 \sim 1982)$ & $11.5(3.3 \sim 31.5)$ \\
\hline & & GG & 22 & $49(27 \sim 72)^{\mathrm{a}}$ & $505(267 \sim 856)$ & $11.1(6.4 \sim 14.9)$ \\
\hline SNP8 & CYP2B6 & $\mathrm{CC}$ & 36 & $66(27 \sim 185)$ & $57(22 \sim 173)$ & $0.98(0.16 \sim 2.79)$ \\
\hline \multirow[t]{2}{*}{$(\mathrm{C}>\mathrm{T})$} & & CT & 38 & $82(41 \sim 195)$ & $51(14 \sim 95)$ & $0.68(0.18 \sim 2.26)$ \\
\hline & & TT & 9 & $54(17 \sim 99)^{\mathrm{b}}$ & $55(13 \sim 100)$ & $1.14(0.13 \sim 4.07)$ \\
\hline
\end{tabular}


decreased $\mathrm{K}_{\mathrm{m}}$ and increased $\mathrm{CL}_{\mathrm{int}}$ for some genotypes of CYP2E1. Km for CYP2E1 -333TA decreased to $54 \%$ and $78 \%$ in SNP3 AA group when compared with GG and GA group, respectively $(\mathrm{P}=0.006,0.04)$. Moreover, Clint of CYP2E1 7632TA increased to $270 \%$ in POR SNP3 GA carriers as compared with GG carriers. SNP3 also showed significantly lower $\mathrm{V}_{\mathrm{m}}$ and $\mathrm{CL}_{\text {int }}$ for $C Y P 2 A 6^{*} 1{ }^{*} 1$, as indicated by the most obvious case where the $\mathrm{V}_{\text {max }}$ for $C Y P 2$ $A 6{ }^{*} 1 /{ }^{*} 1$ decreased to $37 \%$ and Clint to $76 \%$ in SNP3 (G>A) GA carriers as compared with GG group.

Only individuals with CYP2B6-785AG genotypes were significantly influenced by POR SNP4, with a slightly higher $\mathrm{K}_{\mathrm{m}}$ and lower $\mathrm{CL}_{\text {int }}$ in POR SNP4 (T>C) CC carriers as compared with TC group.

Table 4. Effect of POR SNPs on $\mathrm{K}_{\mathrm{m}^{\prime}}, \mathrm{V}_{\text {max }}$ and $\mathrm{CL}_{\text {int }}$ of 10 polymorphic CYPs. For all polymorphic CYPs, only the genotypes for CYPs in which the overall $\mathrm{K}_{\mathrm{m}}, \mathrm{V}_{\max }$ and/or $\mathrm{CL}_{\text {int }}$ are/is significantly affected by POR SNPs are shown. SNP, Single Nucleotide Polymorphism; $\mathrm{K}_{\mathrm{m}}$ values are in $\mu \mathrm{M} ; \mathrm{V}_{\max }$ values are in $\mathrm{pmol} \cdot \mathrm{min}^{-1} \cdot \mathrm{mg}^{-1}$ protein; $\mathrm{CL}_{\text {int }}$ values are in $\mu \mathrm{l} \cdot \mathrm{min}^{-1} \cdot \mathrm{mg}^{-1}$ protein. SNP1, rs3823884; SNP2, rs1135612; SNP3, rs10954732; SNP4, rs4732515; SNP5,rs2286822; SNP6, rs2286823;SNP7,2302432; SNP8, rs1057868; SNP9, rs2302433. All the $\mathrm{P}$ value are the adjusted one after correction

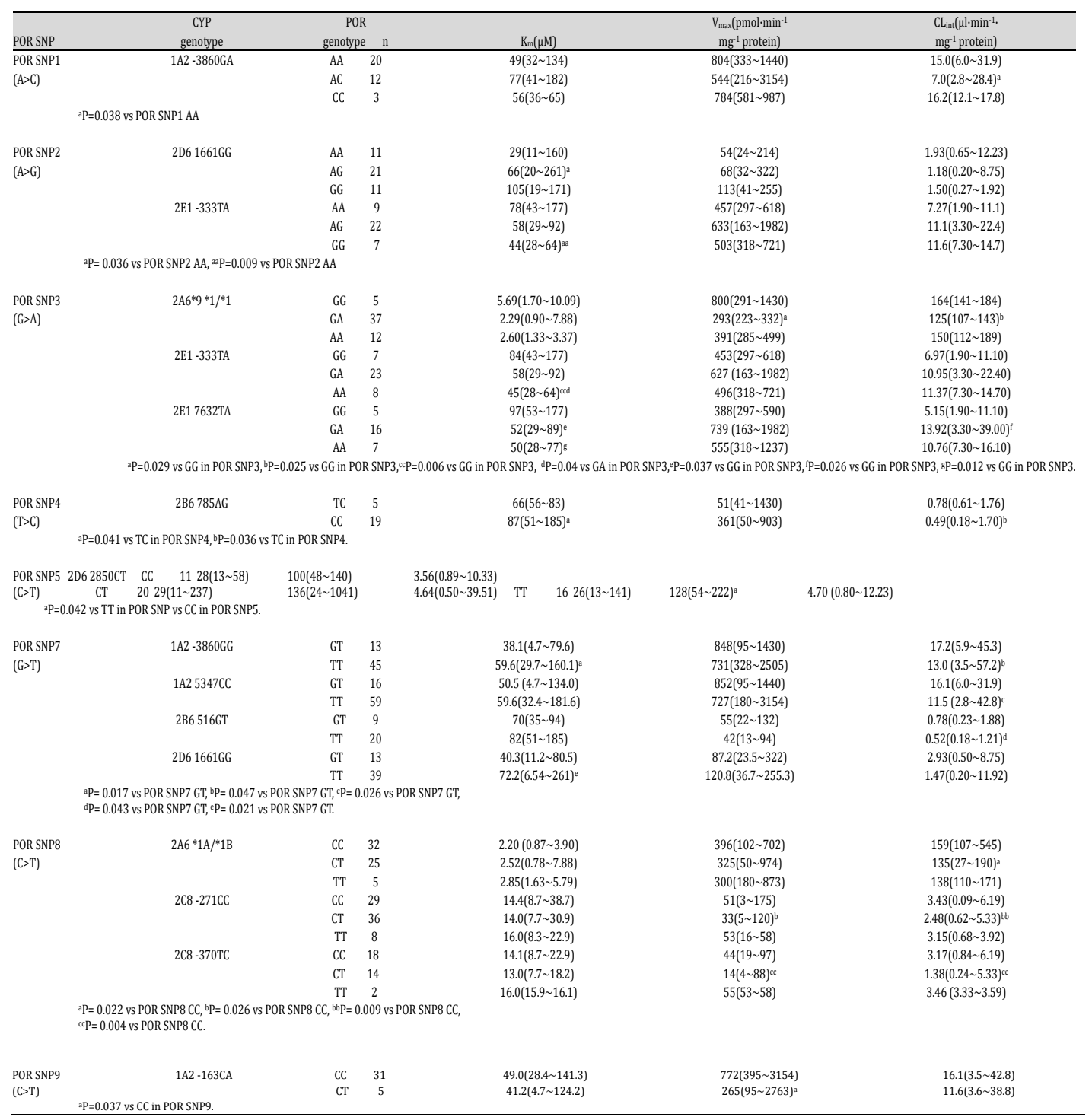


A markedly higher $\mathrm{V}_{\max }$ for CYP2D6 2850CT was found in samples with POR SNP5 mutations, the $\mathrm{V}_{\text {max }}$ increased to $128 \%$ for CYP2D6 2850CT in POR SNP5(C $>\mathrm{T}$ ) TT group as compared with CC group.

SNP7 appeared to have a significant effect on activities of CYP1A2, CYP2B6 and CYP2D6. In this study only POR SNP7 GT and TT were detected, while allele GG was not found. POR SNP7 TT carriers showed an increased $\mathrm{K}_{\mathrm{m}}$ in samples genotyped as CYP1A2 -3860GG as well as CYP2D6 1661GG and a decreased $\mathrm{CL}_{\mathrm{int}}$ in samples genotyped as CYP1A2 -3860GG, 5347CC and CYP2B6 516GT. For the CYP2D6 1661GG genotype, the results indicated higher activities $\left(\mathrm{CL}_{\text {int }}\right)$ in individuals with homozygous mutations for the POR SNP7 genotype as compared with heterozygotes.

POR SNP8 carriers showed a significantly decreased $\mathrm{V}_{\max }$ for samples genotyped as CYP2C8 -271CC and -370TC as well as a decreased $\mathrm{CL}_{\text {int }}$ for $C Y P 2 A 6^{*} 1 A{ }^{*} 1 B, C Y P 2 C 8-271 C C$, and $-370 T C$ genotypes. Obviously, for CYP2C8 -271CC, livers carrying POR SNP8 mutant heterozygotes had a decrease in $\mathrm{V}_{\max }$ by $35 \%$ and $\mathrm{CL}_{\text {int }}$ decreased by $28 \%$, as compared with wild-type $(\mathrm{P}=0.026,0.009)$. For $C Y P 2 C 8-370 T C$, livers carrying POR SNP8 mutant heterozygotes had a decrease inV $\mathrm{V}_{\text {max }}$ by $68 \%$ and $\mathrm{CL}_{\text {int }}$ decreased by $56 \%$, as compared with wild-type $(\mathrm{P}=0.004)$.

In this study, only POR SNP9 CC and CT were detected, and no TT allele was discovered. For livers genotyped as CYP1A2-163CA, a significantly decreased $\mathrm{K}_{\mathrm{m}}(16 \%)$ and $\mathrm{V}_{\max }(66 \%)$ was noted in POR SNP9 CT carriers compared with CC carriers.

Effect of Multiple-Site Gene Polymorphisms (MSGP). There are 38 POR MSGPs; however, only 5 MSGPs (listed from MSGP1 to MSGP5) had a sufficient number of individuals (more than or equal to 5, Table 5) to be analyzed for the effect of MSGP on CYPs activities. The effect of these POR MSGPs were determined by the comparison of $\mathrm{K}_{\mathrm{m}}, \mathrm{V}_{\text {max }}, \mathrm{CL}_{\text {int }}$ of CYPs between different MSGPs according to nonparametric methods.

\section{MSGP Positive with SNP Negative}

When combining POR SNP1 with other SNPs, livers carrying SNP1 showed diminished activity for CYP2B6, indicated by the $\mathrm{V}_{\max }$ and $\mathrm{CL}_{\text {int }}$ in MSGP5 group decreasing by $48 \%$ $(P<0.01)$ and $54 \%$, respectively, as compared with MSGP4 group (Fig. 2). Here, MSGP5 contained an SNP1 mutation while MSGP4 did not. It is somewhat surprising that SNP1 alone did not show any significant influence on the overall activity of CYP2B6 nor on the activity of polymorphic CYP2B6.

\section{MSGP Negative with SNP Positive}

In contrast to the results above, the POR SNP1 alone was associated with significantly reduced $\mathrm{CL}_{\text {int }}$ for $C Y P 1 A 2$-3860GA. However, no significant difference was observed in the kinetic parameters of CYP1A2 between the MSGP4 and MSGP5 groups, which differed in the presence of the SNP1 polymorphism (MSGP5). Similar examples were identified in the effect

Table 5. POR multiple-site gene polymorphisms (MSGP) in human liver microsomes.MSGP, multiple-site gene polymorphism of POR; SNP1, rs3823884; SNP2, rs1135612; SNP3,rs10954732; SNP4, rs4732515; SNP5, rs2286822; SNP6, rs2286823; SNP7, rs2302432; SNP8, rs1057868; SNP9, rs2302433. Only 5 MSGPs (listed from MSGP1 to MSGP5) had a sufficient number of individuals (more than or equal to 5). These 5 MSGPs accounted for a number of 32 livers. "Others" mean that there were 45 livers left which belong to the MSGPs with sample numbers less than 5

\begin{tabular}{|c|c|c|c|c|c|c|c|c|c|c|}
\hline \multirow[b]{2}{*}{$\begin{array}{l}\text { MSGP } \\
\text { genotype }\end{array}$} & \multicolumn{10}{|c|}{ POR SNP alleles } \\
\hline & $\begin{array}{l}\text { SNP1 } \\
(A>C)\end{array}$ & $\begin{array}{l}\text { SNP2 } \\
(A>G)\end{array}$ & $\begin{array}{l}\text { SNP3 } \\
(G>A)\end{array}$ & $\begin{array}{l}\text { SNP4 } \\
(\mathrm{T}>\mathrm{C})\end{array}$ & $\begin{array}{l}\text { SNP5 } \\
(\mathrm{C}>\mathrm{T})\end{array}$ & $\begin{array}{l}\text { SNP6 } \\
(G>T)\end{array}$ & $\begin{array}{l}\text { SNP7 } \\
(G>T)\end{array}$ & $\begin{array}{l}\text { SNP8 } \\
(\mathrm{C}>\mathrm{T})\end{array}$ & $\begin{array}{l}\text { SNP9 } \\
(\mathrm{C}>\mathrm{T})\end{array}$ & $\mathrm{n}$ \\
\hline MSGP1 & AC & AG & GA & TC & CT & GT & GT & $\mathrm{CC}$ & $\mathrm{CC}$ & 6 \\
\hline MSGP2 & AA & AG & GA & CC & CC & GT & TT & CT & CC & 5 \\
\hline MSGP3 & $\mathrm{AA}$ & AG & GA & CC & $\mathrm{CT}$ & GT & $\mathrm{TT}$ & $\mathrm{CT}$ & CC & 9 \\
\hline MSGP4 & AA & GG & AA & $\mathrm{CC}$ & TT & TT & TT & $\mathrm{CC}$ & CC & 6 \\
\hline MSGP5 & $\mathrm{AC}$ & GG & AA & CC & TT & TT & TT & CC & CC & 6 \\
\hline Others & - & - & - & - & - & - & - & - & - & 45 \\
\hline
\end{tabular}


of SNP7 alone on some genotypes of CYP1A2, while no effect on activities was seen between MSGP5 and MSGP1 groups, where MSGP5 contains the SNP7 homozygote mutation and MSGP1 does not.

\section{Different Effect between MSGP} and SNP

Another finding was that the magnitude of the differences in the effect between one SNP alone and an MSGP on enzyme activities of CYPs differed. The $\mathrm{K}_{\mathrm{m}}$ and $\mathrm{CL}_{\text {int }}$ of CYP2D6 increased and decreased by $90 \%$ and $60 \%$, respectively, with the MSGP3 genotype which contained the SNP5 mutation as compared with MSGP2 group. As for SNP5 alone, the $\mathrm{V}_{\max }$ for CYP2D6 $2850 C T$ increased by $28 \%$, implying a more profound effect of the MSGP than the SNP alone on activity of CYP2D6.

\section{Discussion}

Precision medicine_ENREF_1, proposing "providing the right patient with the right drug at the right dose at the right time", represents a major goal for 21stcentury medicine [26, 27]. It is well recognized that interindividual variations in drug response, including a lack of efficacy and adverse drug reactions represent the major challenges for personalized medicine. Although a drug effect is complex and depends on many factors, some human gene polymorphisms already have been associated with substantial differences in the metabolism or effects of drugs [28], and some are now being used to predict toxic metabolite-related disease or a clinical response [29-35]_ENREF_1._ENREF_1However, as the principal electron donor for the drug metabolizing CYPs, little is known about the effect of POR gene polymorphisms on the activities of CYPs with different genotypes.

The perfect linkage between rs4732515, rs4732516 and rs2302431 has not been reported previously. Perfect linkage $\left(r^{2}=1\right)$ was detected between $r s 3815455$, rs 41301394 and rs1057868, and between rs10239977 and rs1057870, and a relatively strong linkage $\left(r^{2} \geq 0.95\right)$ was observed between rs2302432 and rs2228104 (Fig. 1). Some other perfect linkages observed in previous studies [36-38] were _ENREF_7not detected in our study. These disparities may stem from the different number of specimens and the ethnicity of the populations studied. Our present study confirmed several of the already reported common POR single nucleotide polymorphisms (SNPs) and allele frequencies and are consistent with the data in Chinese population obtained in a previous report [38]. 


\section{Cellular Physiology Cell Physiol Biochem 2018;47:1604-1616

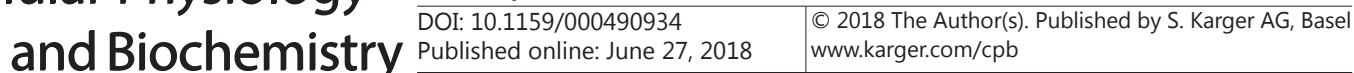

Fang et al.: POR Polymorphism Affect Polymorphic Cyps

It should be emphasized that effect of POR SNPs on the overall activity of CYPs differed from that exerted on polymorphic CYPs. POR SNP2 and SNP8 showed significantly decreased overall $\mathrm{K}_{\mathrm{m}}$ of CYP2E1 and CYP2B6, respectively. The impact of POR SNPs on the activity of a given CYP depended on the genotype. When CYP activities were characterized by CYP genotypes, several additional CYPs, including CYP1A2, 2A6, 2C8 and CYP2D6 contained specific genotypes that exhibited significantly altered kinetic parameters in association with POR SNPs, as did specific genotypes for CYP2B6, and 2E1. POR SNP2 showed a significantly decreased $\mathrm{K}_{\mathrm{m}}$ for CYP2E1 by 18\%; when CYP2E1 activity was analyzed for the different $2 E 1$ genotypes, only samples genotyped as CYP2E1 333TA showed a significant decrease in $\mathrm{CL}_{\text {int }}$ by $26 \%$. No significant effect on the activity of other CYP2E1 genotypes was found with POR SNP2.

We found that the effect of multiple-site gene polymorphisms (MSGPs) on CYP activity did not always correspond to the effect seen with a single POR SNP. The effect of the POR SNP1 on CYP2B6 activity was not significant when it was the only POR mutation, but when it was combined with other POR SNPs, as in MSGP5, it showed significantly decreased activity of CYP2B6; note the difference in CYP2B6 activity between MSGP5 and MSGP4 (Fig. 2), the latter of which lacks the SNP1 mutation. A second example is with CYP1A2, where SNP1 alone was significantly associated with altered CYP1A2 activity but had no effect when combined with other POR SNPs, as in MSGP5. The magnitude of an effect can also differ between SNPs and MSGPs: SNP5 showed significantly increased CYP2D6 activity but had a greater effect when combined with other SNPs in MSGP3 compare with MSGP2. Taken together, the co-occurrences of mutations in POR might exert synergistic or compensating effects on CYPs activities.

Interestingly, our study indicates that the intronic POR SNPs resulted in dramatically altered activities of polymorphic CYPs, which was in partial agreement with an in vitro study [19] assessing more globally the influence of 46 POR mutations and an in vivo study [39] on effect of 5 intronic and one exonic POR mutations on CYP1A2 activity. However, CYP genotypes were not examined in these studies. We note that SNP1, which is a mutation in the 3 '-untranslated gene region, was significantly associated with reduced activities of CYP1A2, suggesting that this SNP play a role in CYP activities despite being in a non-coding region of the gene. Consistent with our study, studies focusing on common intronic and silent polymorphisms in the CYP2D6 and CYP2C19 genes [40, 41] both indicated that intronic CYP SNPs were significantly associated with CYP activity. Studies on possible mechanisms are currently in progress. Emerging evidence [42] indicates that non-coding genetic variants play an important role in gene regulation by influencing the transcriptional activity, splicing efficiency, or altering the splicing site of their host genes. Significantly altered POR expression and activity associated with $P O R$ mutations in introns and 5'-untranslated region, leading to altered CYP activity, according to our previous study [16] may help demonstrate this.

In conclusion, our study is the first to investigate systematically the effect of POR single nucleotide polymorphisms (SNPs) alone and multiple-site gene polymorphisms (MSGP) on the activities of 10 highly polymorphic CYPs in a large collection of normal Chinese liver samples. The effect of POR gene polymorphisms on CYP activities varied not only in a CYPdependent manner, but more importantly in a CYP genotype-dependent manner. Moreover, the effect of POR MSGPs on CYP activities was not always consistent with that of single POR SNPs, and POR MSGP analysis appears to be more appropriate for accurately evaluating the effect of POR mutations on CYP activity. This work may have important implications for providing a convincing demonstration of the potential functional impact of $P O R$ gene polymorphisms on activities of polymorphic CYPs while at the same time revealing a hithertounrecognized effect of MSGPs on CYP drug metabolism, which may help elucidate the genetic basis underlying substantial changes in drug metabolism and facilitate the development of personalized medicine. 


\section{Cellular Physiology Cell Physiol Biochem 2018;47:1604-1616 \begin{tabular}{l|l} 
DOI: 10.1159/000490934 & Cond Biochemistry \\
Published online: June 27, 2018 & $\begin{array}{l}\text { O 2018 The Author(s). Published by S. Karger AG, Basel } \\
\text { www.karger.com/cpb }\end{array}$
\end{tabular}}

Fang et al.: POR Polymorphism Affect Polymorphic Cyps

\section{Acknowledgements}

This work was supported by the National Natural Science Foundation of China (No.81473279) and (No. 81673507).

\section{Disclosure Statement}

The authors declare no competing financial interests.

\section{References}

1 Pandey AV, Fluck CE:NADPH P450 oxidoreductase: Structure, function, and pathology of diseases. Pharmacol Ther 2013;138:229-254.

2 Zanger UM, Schwab M: Cytochrome P450 enzymes in drug metabolism: Regulation of gene expression, enzyme activities, and impact of genetic variation. Pharmacol Ther 2013;138:103-141.

3 Bridges A, Gruenke L, Chang YT, Vakser IA, Loew G, Waskell L: Identification of the binding site on cytochrome P450 2B4 for cytochrome b5 and cytochrome P450 reductase. J Biol Chem 1998;273:1703617049.

-4 Huang N, Miller WL: Genetics of P450 oxidoreductase: Sequence variation in 842 individuals of four ethnicities and activities of 15 missense mutations. Proc Natl Acad Sci of U S A 2008;105:1733-1738.

5 Flück CE, Tajima T, Pandey AV, Arlt W, Okuhara K, Verge CF, Jabs EW, Mendonça BB, Fujieda K, Miller WL: Mutant P450 oxidoreductase causes disordered steroidogenesis with and without antley-bixler syndrome. Nature Genetics 2004;36:228-230.

6 Huang N, Pandey AV, Agrawal V, Reardon W, Lapunzina PD, Mowat D, Jabs EW, Van Vliet G, Sack J, Fluck CE, Miller WL: Diversity and function of mutations in P450 oxidoreductase in patients with antley-bixler syndrome and disordered steroidogenesis. Am J Hum Genet 2005;76:729-749.

7 Sandee D, Morrissey K, Agrawal V, Tam HK, Kramer MA, Tracy TS, Giacomini KM, Miller WL: Effects of genetic variants of human P450 oxidoreductase on catalysis by CYP2D6 in vitro. Pharmacogenet Genomics 2010;20:677-686.

8 Agrawal V, Choi JH, Giacomini KM, Miller WL: Substrate-specific modulation of CYP3A4 activity by genetic variants of cytochrome P450 oxidoreductase. Pharmacogenet Genomics 2010;20:611-618.

-9 Yang G, Fu Z, Chen X, Yuan H, Yang H, Huang Y, Ouyang D, Tan Z, Tan H, Huang Z, Zhou H: Effects of the CYP oxidoreductase Ala503Val polymorphism on CYP3A activity in vivo: A randomized, open-label, crossover study in healthy chinese men. Clin Ther 2011;33:2060-2070.

10 Zhang JJ, Zhang H, Ding XL, Ma S, Miao LY: Effect of the P450 oxidoreductase 28 polymorphism on the pharmacokinetics of tacrolimus in chinese healthy male volunteers. Eur J Clin Pharmacol 2013;69:807-812.

11 Zhou J, Wen Q, Li SF, Zhang YF, Gao N, Tian X, Fang Y, Gao J, Cui MZ, He XP, Jia LJ, Jin H, Qiao HL: Significant change of cytochrome P450s activities in patients with hepatocellular carcinoma. Oncotarget 2016;7:50612-50623.

12 Gao N, Tian X, Fang Y, Zhou J, Zhang H, Wen Q Jia L, Gao J, Sun B, Wei J, Zhang Y, Cui M, Qiao H: Gene polymorphisms and contents of cytochrome P450s have only limited effects on metabolic activities in human liver microsomes. Eur J Pharm Sci 2016;92:86-97.

13 Zhang H, Gao N, Tian X, Liu T, Fang Y, Zhou J, Wen Q, Xu B, Qi B, Gao J, Li H, Jia L, Qiao H: Content and activity of human liver microsomal protein and prediction of individual hepatic clearance in vivo. Sci Rep 2015;5:17671.

14 Gao J, Zhou J, He XP, Zhang YF, Gao N, Tian X, Fang Y, Wen Q Jia LJ, Jin H, Qiao HL: Changes in cytochrome P450s-mediated drug clearance in patients with hepatocellular carcinoma in vitro and in vivo: A bottom-up approach. Oncotarget 2016;7:28612-28623.

15 Zhang HF, Wang HH, Gao N, Wei JY, Tian X, Zhao Y, Fang Y, Zhou J, Wen Q, Gao J, Zhang YJ, Qian XH, Qiao HL: Physiological content and intrinsic activities of 10 cytochrome P450 isoforms in human normal liver microsomes. J Pharmacol Exp Ther 2016;358:83-93. 


\section{Cellular Physiology Cell Physiol Biochem 2018;47:1604-1616 \begin{tabular}{l|l} 
and Biochemistry Published online: June 27, 2018 & $\begin{array}{l}\text { C } 2018 \text { The Author(s). Published by S. Karger AG, Basel } \\
\text { www.karger.com/cpb }\end{array}$ \\
\hline
\end{tabular}}

Fang et al.: POR Polymorphism Affect Polymorphic Cyps

-16 Zhang HF, Li ZH, Liu JY, Liu TT, Wang P, Fang Y, Zhou J, Cui MZ, Gao N, Tian X, Gao J, Wen Q Jia LJ, Qiao HL: Correlation of cytochrome P450 oxidoreductase expression with the expression of 10 isoforms of cytochrome P450 in human liver. Drug Metab Dispos 2016;44:1193-1200.

17 Zhang H, Gao N, Liu T, Fang Y, Qi B, Wen Q, Zhou J, Jia L, Qiao H: Effect of cytochrome b5 content on the activity of polymorphic CYP1A2, 2B6, and 2E1 in human liver microsomes. PLoS One 2015;10:e0128547.

18 Gomes AM, Winter S, Klein K, Turpeinen M, Schaeffeler E, Schwab M, Zanger UM: Pharmacogenomics of human liver cytochrome P450 oxidoreductase: Multifactorial analysis and impact on microsomal drug oxidation. Pharmacogenomics 2009;10:579-599.

19 Hart SN, Wang S, Nakamoto K, Wesselman C, Li Y, Zhong XB: Genetic polymorphisms in cytochrome P450 oxidoreductase influence microsomal P450-catalyzed drug metabolism. Pharmacogenet Genomics 2008;18:11-24.

20 Agrawal V, Huang N, Miller WL: Pharmacogenetics of P450 oxidoreductase: Effect of sequence variants on activities of CYP1A2 and CYP2C19. Pharmacogenet Genomics 2008;18:569-576.

21 Kaspera R, Naraharisetti SB, Evangelista EA, Marciante KD, Psaty BM, Totah RA: Drug metabolism by CYP2C8.3 is determined by substrate dependent interactions with cytochrome P450 reductase and cytochrome b5. Biochem Pharmacol 2011;82:681-691.

22 Subramanian M, Agrawal V, Sandee D, Tam HK, Miller WL, Tracy TS: Effect of P450 oxidoreductase variants on the metabolism of model substrates mediated by CYP2C9.1, CYP2C9.2, and CYP2C9.3. Pharmacogenet Genomics 2012;22:590-597.

-23 Bradford MM: A rapid and sensitive method for the quantitation of microgram quantities of protein utilizing the principle of protein-dye binding. Anal Biochem 1976;72:248-254.

24 Gabriel S, Ziaugra L, Tabbaa D: SNP genotyping using the Sequenom MassARRAY iPLEX platform. Current protocols in human genetics 2009; Chapter 2:Unit 2.12.

25 Thomas RK, Baker AC, Debiasi RM, Winckler W, Laframboise T, Lin WM, Wang M, Feng W, Zander T, MacConaill L, Lee JC, Nicoletti R, Hatton C, Goyette M, Girard L, Majmudar K, Ziaugra L, Wong KK, Gabriel S, Beroukhim R, Peyton M, Barretina J, Dutt A, Emery C, Greulich H, Shah K, Sasaki H, Gazdar A, Minna J, Armstrong SA, Mellinghoff IK, Hodi FS, Dranoff G, Mischel PS, Cloughesy TF, Nelson SF, Liau LM, Mertz K, Rubin MA, Moch H, Loda M, Catalona W, Fletcher J, Signoretti S, Kaye F, Anderson KC, Demetri GD, Dummer R, Wagner S, Herlyn M, Sellers WR, Meyerson M, Garraway LA: High-throughput oncogene mutation profiling in human cancer. Nature genetics 2007;39:347-351.

26 Schork NJ: Personalized medicine: Time for one-person trials. Nature 2015;520:609-611.

27 Wilson ID: Drugs, bugs, and personalized medicine: Pharmacometabonomics enters the ring. Proc Natl Acad Sci U S A 2009;106:14187-14188.

28 Gao J, Tian X, Zhou J, Cui MZ, Zhang HF, Gao N, Wen Q, Qiao HL: From genotype to phenotype: Cytochrome P450 2D6-mediated drug clearance in humans. Mol Pharm 2017;14:649-657.

29 Chasman DI, Posada D, Subrahmanyan L, Cook NR, Stanton VP, Jr., Ridker PM: Pharmacogenetic study of statin therapy and cholesterol reduction. JAMA 2004;291:2821-2827.

-30 Weinshilboum R: Inheritance and drug response. N Engl J Med 2003;348:529-537.

-31 Evans WE, Relling MV: Pharmacogenomics: Translating functional genomics into rational therapeutics. Science 1999;286:487-491.

-32 Gao J, Wang Z, Wang GJ, Zhang HX, Gao N, Wang J, Wang CE, Chang Z, Fang Y, Zhang YF, Zhou J, Jin H, Qiao HL: Higher CYP2E1 activity correlates with hepatocarcinogenesis induced by diethylnitrosamine. J Pharmacol Exp Ther 2018;365:398-407.

-33 Gao J, Wang GJ, Wang Z, Gao N, Li J, Zhang YF, Zhou J, Zhang HX, Wen Q, Jin H, Qiao HL: High CYP2E1 activity correlates with hepatofibrogenesis induced by nitrosamines. Oncotarget 2017;8:112199-112210.

-34 He L, He T, Farrar S, Ji L, Liu T, Ma X: Antioxidants maintain cellular redox homeostasis by elimination of reactive oxygen species. Cell Physiol Biochem 2017;44:532-553.

35 Zhou C, Huang J, Chen J, Lai J, Zhu F, Xu X, Wang DW: CYP2J2-derived eets attenuated angiotensin ii-induced adventitial remodeling via reduced inflammatory response. Cell Physiol Biochem 2016;39:721-739.

-36 Saito Y, Yamamoto N, Katori N, Maekawa K, Fukushima-Uesaka H, Sugimoto D, Kurose K, Sai K, Kaniwa N, Sawada J, Kunitoh H, Ohe Y, Yoshida T, Matsumura Y, Saijo N, Okuda H, Tamura T: Genetic polymorphisms and haplotypes of POR, encoding cytochrome P450 oxidoreductase, in a japanese population. Drug Metab Pharmacokinet 2011;26:107-116. 


\section{Cellular Physiology Cell Physiol Biochem 2018;47:1604-1616 \begin{tabular}{l|l} 
DOI: 10.1159/000490934 & O 2018 The Author(s). Published by S. Karger AG, Basel \\
www.karger.com/cpb
\end{tabular} \\ Fang et al.: POR Polymorphism Affect Polymorphic Cyps}

-37 Tomkova M, Marohnic CC, Gurwitz D, Seda O, Masters BS, Martasek P: Identification of six novel P450 oxidoreductase missense variants in ashkenazi and moroccan jewish populations. Pharmacogenomics 2012;13:543-554.

-38 Huang N, Agrawal V, Giacomini KM, Miller WL: Genetics of P450 oxidoreductase: Sequence variation in 842 individuals of four ethnicities and activities of 15 missense mutations. Proc Natl Acad Sci U S A 2008;105:1733-1738.

-39 Dobrinas M, Cornuz J, Pedrido L, Cb. E: Influence of cytochrome P450 oxidoreductase genetic polymorphisms on CYP1A2 activity and inducibility by smoking. Pharmacogenet Genomics 2012;22:143151.

40 Toscano C, Klein K, Blievernicht J, Schaeffeler E, Saussele T, Raimundo S, Eichelbaum M, Schwab M, Zanger UM: Impaired expression of CYP2D6 in intermediate metabolizers carrying the $* 41$ allele caused by the intronic SNP 2988G>A: Evidence for modulation of splicing events. Pharmacogenet Genomics 2006;16:755-766.

41 Chaudhry AS, Prasad B, Shirasaka Y, Fohner A, Finkelstein D, Fan Y, Wang S, Wu G, Aklillu E, Sim SC, Thummel KE, Schuetz EG: The CYP2C19 intron 2 branch point SNP is the ancestral polymorphism contributing to the poor metabolizer phenotype in livers with CYP2C19*35 and CYP2C19*2 alleles. Drug Metab Dispos 2015;43:1226-1235.

42 Cooper DN: Functional intronic polymorphisms: Buried treasure awaiting discovery within our genes. Hum Genomics 2010;4:284-288. 